\title{
An Overview of Oil Production Stages: Enhanced Oil Recovery Techniques and Nitrogen Injection
}

\author{
Abubaker H. Alagorni, Zulkefli Bin Yaacob, and Abdurahman H. Nour
}

\begin{abstract}
During the life oil wells, production process usually passes three stages. Primary recovery uses the natural source of energy. Pumps and gas lifting are involved in the primary recovery. The main purpose of secondary recovery process is to maintain the reservoir pressure by either a natural gas flooding or water flooding.

The rise in world oil prices has encouraged the producers to use the new technical developments. Enhanced oil recovery (EOR) is a collection of sophisticated methods, to extract the most oil from a reservoir. EOR can be divided into two major types of techniques: thermal and non-thermal recovery. Each technique has a specific use in a certain type of reservoirs.

Among non-thermal techniques is the gas flooding, where gas is generally injected single or intermittently with water. Flue gas and nitrogen have only limited application as agents of a miscible displacement in deep and high pressure reservoirs.

Although new development processes such as water alternating gas (WAG) or Simultaneous water alternating gas (SWAG), are implemented, there are still some problems encountered by EOR engineers. This paper is discussing the last updating in this field.
\end{abstract}

Index Terms-Enhanced oil recovery (EOR), miscible flooding, nitrogen injection, water alternating gas (WAG).

\section{INTRODUCTION}

Primary and secondary recovery methods including waterflooding or reinjection of produced natural gas, produce on the average about one-third of the original oil in place (OOIP). However, by applying the tertiary recovery (commonly called Enhanced Oil Recovery, EOR), production could reach 40 to $60 \%$ of oil in the reservoir. EOR can generally be divided into two methods; nonthermal and thermal methods. The non-thermal methods include chemical flood, and gas flood. On the other hand the thermal methods involve steam injection, hot water flooding, and situ combustion.

Gas Injection can be miscible or immiscible with oil, they include: liquefied petroleum gases (LPGs) such as propane, methane under high pressure; methane enriched with light hydrocarbons; nitrogen under high pressure; flue gas; carbon dioxide, and nitrogen. There are some advantages when using nitrogen injection in the field. However, even if the

Manuscript received October 15, 2014; revised December 27, 2014.

Abubaker H. Alagorni is with Universiti Malaysia Pahang, Malaysia (email: abohamza1111@yahoo.com)

Z. Bin Yaacob and A. H. Nour Yaacob are with the Faculty of Chemica and Natural Resources Engineering, University of Malaysia Pahang, Malaysia (e-mail: zulyaacob@ump.edu.my, abrahman@ump.edu.my). gas that one wishes to use as a miscible displacement agent is economically available; its use is not without problems. Gases are normally less viscous than typical crude oil. This viscosity difference leads to phenomenon called viscous fingering. In contrast, the main problem, that encounters EOR engineers during gas injection, is that nitrogen (or other flue gases) overrides the other reservoir fluids due to difference in densities between the displaced and displacing fluids. This override usually leads to tonging or Density Fingering. Although techniques were found to decrease the effect of these problems on the oil production rate, new developments are to be devised in order to increase the efficiency of these methods.

\section{OIL PRODUCTION PROCESS}

During the life of a producing oil field, several production stages are encountered. Initially, when a field is brought into production, oil flows naturally to the surface due to current reservoir pressure in the primary stage. As reservoir pressure drops, water is typically injected to boost the pressure to displace the oil in the secondary stage. Lastly, the remaining oil can be recovered by a variety of methods such as $\mathrm{CO}_{2}$ injection, natural gas miscible injection, and steam recovery in a tertiary or enhanced oil recovery (EOR) phase [1].

Primary recovery: Glover (2001) explained all recovery methods, including primary recovery mechanism as it is the stage when the natural energy of the reservoir is used to transport hydrocarbons towards and out of the production wells. The earliest possible determination of the drive mechanism is a primary goal in the early life of the reservoir, as its knowledge can greatly improve the management and recovery of reserves from the reservoir in its middle and later life. There are five important drive mechanisms: (i) Solution gas drive; (ii) Gas cap drive; (iii) Water drive; (iv) Gravity drainage; (v) Combination or mixed drive. These drives can maintain the reservoir pressure, though water drive maintains much higher than the gas drives (Fig. 1).

Solution gas drive: In solution gas drive, the expansion of the dissolved gases in the oil and water provides most of the reservoirs drive energy. Solution Gas Drive is associated to two types of Reservoirs that are related to pressure; under saturated reservoirs (no free gases in oil), drive energy is provided only by the bulk expansion of the reservoir rock and liquids; saturated reservoirs, where the pressure is less than the bubble point pressure. A decline in reservoir pressure causes bubbles of gas to expand. Thus gas expansion is the primary reservoir drive for reservoirs below the bubble point. Oil recovery from this type is typically between $20 \%$ and $30 \%$ of original oil in place (Fig. 1). 


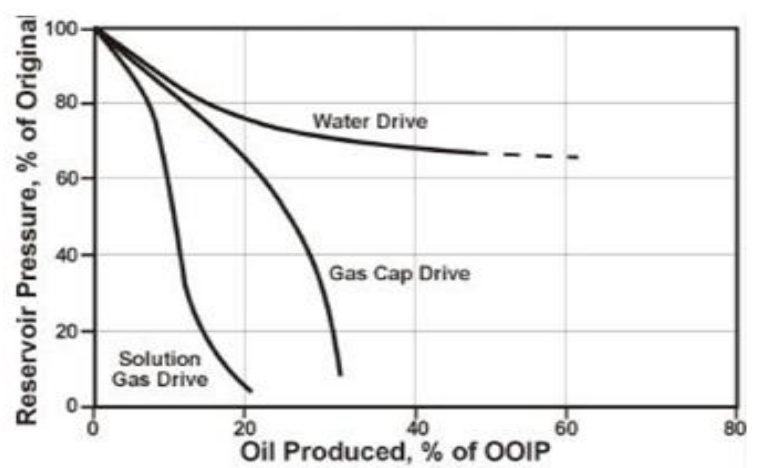

Fig. 1. Reservoir pressure trends by drive mechanism [2].

Gas cap drive: As production continues, the gas cap expands pushing the gas-oil contact (GOC) downwards. Eventually the GOC will reach the production wells and the gas oil ratio (GOR) will increase by large amounts. The recovery of gas cap reservoirs can be (20\% to $40 \%$ OOIP). Produced gas can be separated and immediately injected back into gas cap.

Water drive: The drive energy is provided by an aquifer that interfaces with the oil in the reservoir at the oil-water contact (OWC). As production continues, and oil is extracted from the reservoir, the aquifer expands into the reservoir displacing the oil. The recovery from water driven reservoirs is usually good (20-60\% OOIP). Oil production from a strongly water driven reservoir remains fairly constant until water breakthrough occurs. When water breakthrough does occur the well can either be shut-down, or assisted using gas lift.

Gravity drainage: Gravity Drainage is the fourth drive force that might be considered for drive mechanism where the density differences between oil and gas and water result in their natural segregation in the reservoir. This process can be used as a drive mechanism, but is relatively weak, and in practice is only used in combination with other drive mechanisms.

Combination drive: In practice a reservoir usually incorporates at least two main drive mechanisms. Therefore, Combination or Mixed Drive can be accounted as the fifth type of Drives [2].

Oil lifting by gas or pumps: In addition to the previous drive mechanisms, artificial lifting is considered as a primary recovery, which is a process used to increase pressure within the reservoir, when the natural drive energy of the reservoir is not strong enough to push the oil to the surface. The two main categories of artificial lift include pumping systems and gas lift. Gas lift method injects compressed gas into the well to re-establish pressure, making it produce. On the other hand, jack pumps are submersed and used to lift the oil to the surface [3].

\section{SECONDARY RECOVERY}

After initial discover and production, typical oil reservoirs lose the drive mechanism of gas or water that originally forced the oil to the surface. The second stage of hydrocarbon production in which an external fluid such as water: usually named Water flooding or water injection or gas: referred to as Gas flooding or gas injection, is injected into the reservoir through injection wells located in rock that has fluid communication with production wells [3].

Water flooding: Water Flooding is implemented by injecting water into a set of wells while producing from the surrounding wells. Water flooding projects are generally implemented to accomplish reservoir pressure maintenance and/or dispose of brine water (or produced formation water), and/or as a water drive to displace oil from the injector wells to the producer wells [3].

Gas Flooding: This method is similar to water flooding in principal, and is used to maintain gas cap pressure even if oil displacement is not required. Usually the produced natural gas is re-injected to the reservoir in order to maintain reservoir pressure rather than to displace the hydrocarbon. Later in this paper, gas injection methods are discussed in order to displace oil as well as to maintain the reservoir pressure. These techniques include gases such as Carbon Dioxide or Nitrogen, etc. [4].

Eventually, many oil fields usually produce only $12-15 \%$ of the OIIP. By secondary recovery methods, another 15$20 \%$ may be produced [5].

\section{TERTIARY RECOVERY (ENHANCED OIL RECOVERY)}

Primary production and secondary recovery methods on the average produce less than one-third of the original oil in place (OOlP) [6]. Tertiary Recovery (Enhanced recovery techniques), EOR, can be used to recover additional hydrocarbons. EOR introduces fluids that reduce viscosity and improve flow. These fluids could consist of gases that are miscible with oil such as carbon dioxide or nitrogen, steam, air or oxygen, polymer solutions, gels, surfactantpolymer formulations, alkaline-surfactantpolymerformulations, or microorganism formulations [7]. However, the diagram of the oil recovery stages is shown in Fig. 2 [8].

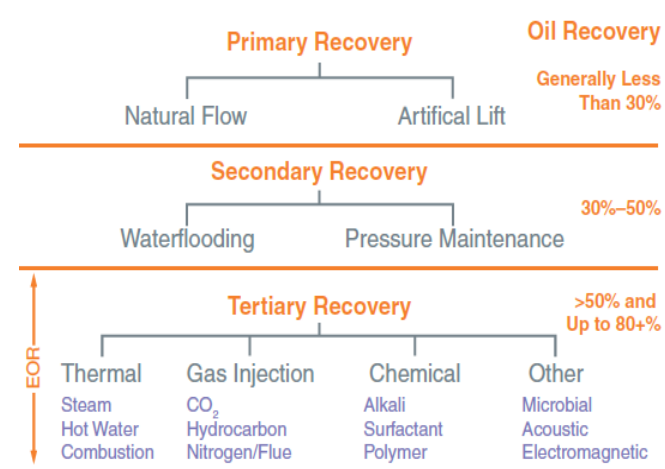

Fig. 2. The different oil recovery stages and the corresponding oil recovery factor [10].

\section{ENHANCED OIL RECOVERY TECHNIQUES}

EOR refers to the recovery of oil through the injection of fluids and energy not normally present in the reservoir [4]. The objectives of the injected fluids are to achieve mainly two purposes; First is to boost the natural energy in the reservoir; second is to interact with the reservoir rock/oil system to create conditions favourable for residual oil recovery that leads to reduce the interfacial tension between the displacing fluid and oil, increase the capillary number, reduce capillary forces, increase the drive water viscosity, 
provide mobility-control, create oil swelling, reduce oil viscosity, alter the wettability of reservoir rock [4]. Enhanced oil recovery can be divided into two thermal and non-thermal recovery [9]. Fig. 2 illustrates oil recovery stages by the different EOR techniques.

\section{THERMAL TECHNIQUES}

Thermal methods raise the temperature of the reservoir to heat the crude oil in the formation and therefore reduce its viscosity and/or vaporise part of the oil and thereby decrease the mobility ratio. The increase in heat reduces the surface tension and increases the permeability of the oil and improves the reservoir seepage conditions. The heated oil may also vaporise and then condense to be produced. This operation, however, requires substantial investment in special equipment. Both methods also hardly damage the well bore structure, as well as pose safety risks in the larger production process. Therefore, thermal methods are not generally USED very often [11].

Steam Injection: Steam is injected into the reservoir either continuously or in cycles. Continuous steam injection involves both injection and production wells, whereas cyclic injection involves one well only which serves as both injection and production well. Steam floods are easier to control than in-situ combustion. For the same pattern size, the response time is $25-50 \%$ lower than the response time for additional production by in-situ combustion [12].

In-situ combustion (ISC): In-situ combustion or fire flooding is a process in which an oxygen containing gas is injected into a reservoir where it reacts with the oil contained within the pore space to create a high temperature self-sustaining combustion front that is propagated through the reservoir. The heat from the combustion thins out the oil around it, causes gas to vaporize from it, and vaporizes the water in the reservoir to steam. Steam, hot water, and gas, all act to drive oil in front of the fire to production wells. Insitu combustion is possible if the crude-oil/rock combination produces enough fuel to sustain the combustion front [4].

Severe corrosion and increased sand oil production are some of the problems that encountered by implementation of this technique [4].

Hot water flooding: Water-flooding in heavy oils is generally not an efficient way of production due to high viscosity of heavy oil compared to water. In hot waterflooding, thermal energy will increase oil mobility, and possibly provide a more sweep efficiency [13]. Injecting, regularly hot fresh to saline brines will improve oil recovery by dropping viscosity and decreasing residual oil saturation. If low salinity waters are injected, clay matrix may swell and therefore clog pore throats. Porosity and permeability can be increased by collapsing some of the interlayer clays, when injecting water with high temperature. According to Seni [14], Burger and others (1985) emphasized that although the incremental gain in production from injecting hot water is substantial compared with that gained from injecting cold water during typical water flood are less significant than those resulting from injecting steam. Operators seldom employ hot water flooding because heat losses in surface lines, wellbore, and formation are greater than the heat losses in the other thermal processes. The heat losses reduce the processes effectiveness in decreasing oil viscosity [15].

\section{NON-THERMAL EOR TECHNIQUES}

\section{A. Chemical Flooding}

The best times for using chemical EOR methods were in the 1980's. Polymer flooding was the most important chemical EOR method. However, since 1990's, production from chemical EOR methods has been insignificant around the world except for China [16]. These processes use chemicals added to water in the injected fluid of a water flood to alter the flood efficiency in such a way as to improve oil recovery by: (i) Increasing water viscosity (polymer floods) (ii) Decreasing the relative permeability to water (cross-linked polymer floods) (iii) Increasing the relative permeability to oil (micellar and alkaline floods) [2].

\section{B. Chemical EOR Types}

Polymer flooding: Polymers improve both vertical and areal sweep efficiency by reducing water-oil ratio. Polymers are injected through water injection wells [17] in order to displace the residual oil. Increasing the displacing fluid's viscosity and lowering its relative permeability through plugging will improve the mobility ratio and this will make an improvement in areal and vertical sweep efficiency [9].

Micellr polymer flooding It is well known that water and oil cannot be mixed until the third component, surfactant or soap, is added to reduce the interfacial tension between oil and water. Since micellar solution makes fluids miscible in the reservoir, almost $100 \%$ of oil can be displaced especially in the presence of alkaline (Sodium Carbonate). However, due to reservoir rock non-uniformity in the field, the amount of oil recovered is reduced. The main objective of micellar injection is to reduce interfacial tension to enhance oil recovery [18]. Micellar solutions are mixtures of surfactants, co-surfactants, electrolytes, hydrocarbon, and water. Surfactants are substances known as surface active agents, such as soap. Co-surfactants are used for stability such as alcohols. Electrolytes are salts used to control viscosity and interfacial tension such as sodium chloride or ammonium sulphate. [9].

Alkaline-surfactant-polymer (ASP) flooding: During waterflooding residual oil is trapped due to low water viscosity and high water-oil interfacial tension, therefore another way is to inject the three chemicals; Alkaline to minimize surface adsorption; Surfactant to lower interfacial tension and stabilizes the emulsion. On the other hand, Polymer is used to increase viscosity and to improve mobility control and sweep efficiency. [17].

\section{Gas Flooding (Injection)}

Gas is generally injected single or intermittently with water and this manner of injection called Water-AlternatingGas (WAG), has become widely practiced over all of world's oil fields [19]. According to miscibility between gas injected and oil displaced, gas injection can be classified into two major types: miscible gas injection and immiscible gas injection. In miscible gas injection, the gas is injected at or above minimum miscibility pressure (MMP) which causes the gas to be miscible in the oil. In contrast in 
immiscible gas injection, flooding by the gas is conducted below MMP. This low pressure injection of gas is used to maintain reservoir pressure to prevent production cut-off and thereby increase the rate of production [9]. In miscible flooding, the incremental oil recovery is obtained by one of the three mechanisms: oil displacement by solvent through the generation of miscibility (i.e. zero interfacial tension between oil and solvent - hence infinite capillary number), oil swelling, and reduction in oil viscosity [19]. Miscible fluids are $100 \%$ soluble in each other. The interfacial tension between miscible fluids is zero. Injection gases include:

LPG injection: Miscible LPG products such as ethane, propane, or butane have first contact miscibility, which means they will be miscible from the first contact with oil. However, LPGs are in such demand as marketable commodity that their use in EOR is limited [4]. In particular, this process uses a slug of propane or other liquefied petroleum gas (2 to $5 \% \mathrm{PV}$ pore volume) followed by natural gas, inert gas, and/or water. Thus, the solvent will bank oil and water ahead, and fully displace all contacted oil [9].

Enriched gas miscible process: In this process, a slug of methane $(\mathrm{C} 1)$ enriched with ethane $(\mathrm{C} 2)$, propane $(\mathrm{C} 3)$, or butane (C4) (10 to $20 \%$ of the PV) and followed by lean gas and/or water is injected from water injection well into the reservoir. When the injected gas contacts virgin reservoir oil, C1-C3 are quenched from the injected gas and absorbed into the oil [9]. The injected HC solvent is usually displaced with cheaper chase leaner or inert gas like Methane or Nitrogen.

At reservoir conditions the most usual problem occurs with the hydrocarbon miscible flood is the gravity over-ride because of its lighter density than the oil and water. So that in any miscible flood the Minimum Miscibility Pressure (MMP) plays the most major role to overcome this problem. As a remedial factor the solvent is to be injected at or above the MMP of the reservoir fluid. Once it becomes miscible then it improves the sweep efficiency and fallouts in optimum recovery [20].

Carbon dioxide $\left(\mathrm{CO}_{2}\right)$ injection is one of the most proven of these methods. Almost pure $\mathrm{CO}_{2}(>95 \%$ of the overall composition) has the property of mixing with the oil to swell it, make it lighter, detach it from the rock surfaces, and causing the oil to flow more freely within the reservoir so that it can be "swept up" in the flow from injector well to producer well [21]. Flooding a reservoir with $\mathrm{CO}_{2}$ can occur either miscibility or immiscibly. Miscible $\mathrm{CO}_{2}$ displacement is only achieved under a specific combination of conditions, which are set by four variables: reservoir temperature, reservoir pressure, injected gas composition, and oil chemical composition. From a fundamental point of view, $\mathrm{CO}_{2}$ EOR works on a very simple principle, namely, that given the right physical conditions, $\mathrm{CO}_{2}$ will mix miscibly with oil, acting much like a thinning agent, the same way that gasoline does with motor oil. After miscible mixing, the fluid is displaced by a chase phase, typically water [1].

\section{Nitrogen Injection}

The nitrogen injection can be used as a substitute for $\mathrm{CO}_{2}$ in deep light to medium oil reservoirs mainly containing $\mathrm{C} 1$ to C7 components. It is applicable in both the Sandstone and Carbonate reservoirs. Nitrogen itself is an inert gas that gets miscible at very high pressure and efficiently reduces the oil viscosity and provides efficient miscible displacement [20]. Based on past studies, nitrogen injection could recover up to $45-90 \%$ of initial reserves. Nitrogen was used back to 50's when it played a crucial role in the petroleum industry, such as in well completion and well work over[22]. Nitrogen has long been successfully used as the injection fluid for EOR and widely used in oil field operations for gas cycling, reservoir pressure maintenance, and gas lift. The costs and limitations on the availability of natural gas and $\mathrm{CO}_{2}$ have made nitrogen an economic alternative for oil recovery by miscible gas displacement.

Nitrogen immiscible flooding: Gas cap displacement: The reservoir is a large anticlinal structure with a sizable gas cap. Gas is being injected into the crest of the structure to maintain the pressure, to recover the hydrocarbon liquids in the gas cap, and to stabilize the gas/oil contact. It is generally known that the nitrogen being injected will serve to maintain the pressure in the reservoir, as well as serve to take advantage of the structure of the field and the gravity difference between the injected fluid and the reservoir fluid. See Fig. 3.

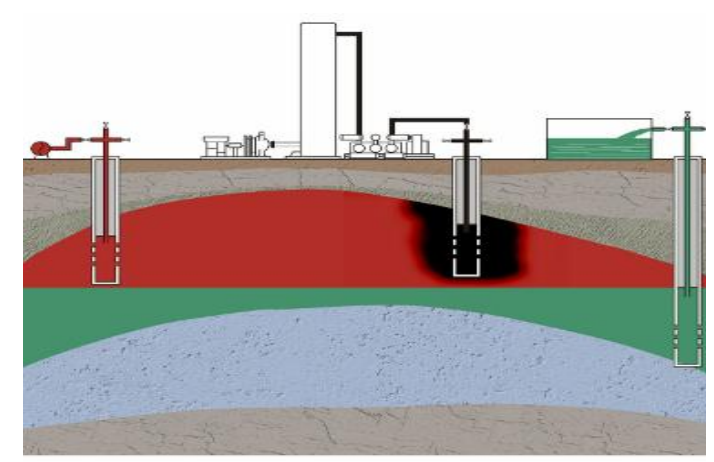

Fig. 3. Gas cap displacement [23].

Nitrogen miscibility displacement mechanism: There are three types of miscibility including; First contact miscibility; Multi- contact miscibility; Vaporizing masstransfer miscibility [24].

Multi-contact miscibility: In miscible flood processes some combination of transfer of components from the oil displaced to the injected fluid and from the injected fluid to the oil takes place as the phases flow through the porous medium. Some hydrocarbon gases, with a high proportion of intermediate molecular weight components (C3, C4, andC5) are miscible with oil under pressure and temperature conditions encountered in some oil reservoirs. Moreover, under much wider condition the displacement of oil by hydrocarbon gases may lead, through component exchange between oil and the gas, to creation of transition zone in which the composition varies continuously between the composition of the displacing fluid and the composition of the oil. Light to intermediate components are exchanged between oil and injected fluid. A transition zone spreads out in which both fluids are miscible. This type of miscibility is called multiple-contact miscibility, and subdivided into vaporizing gas drive, condensing gas drive. [25].

Vaporising gas drive: It is a particular case of multiple contact miscibility, based on the vaporization of 
intermediate components from the reservoir oil to the injected gas creating a miscible transition zone. The C2-C5 fraction is preferently extracted. This mainly occurs at high pressure, by injecting natural (hydrocarbon) gas, flue gas or nitrogen. When Nitrogen is injected at high pressure, it can form a miscible slug which aids in freeing the oil from the reservoir rock, Fig. 4 [10].

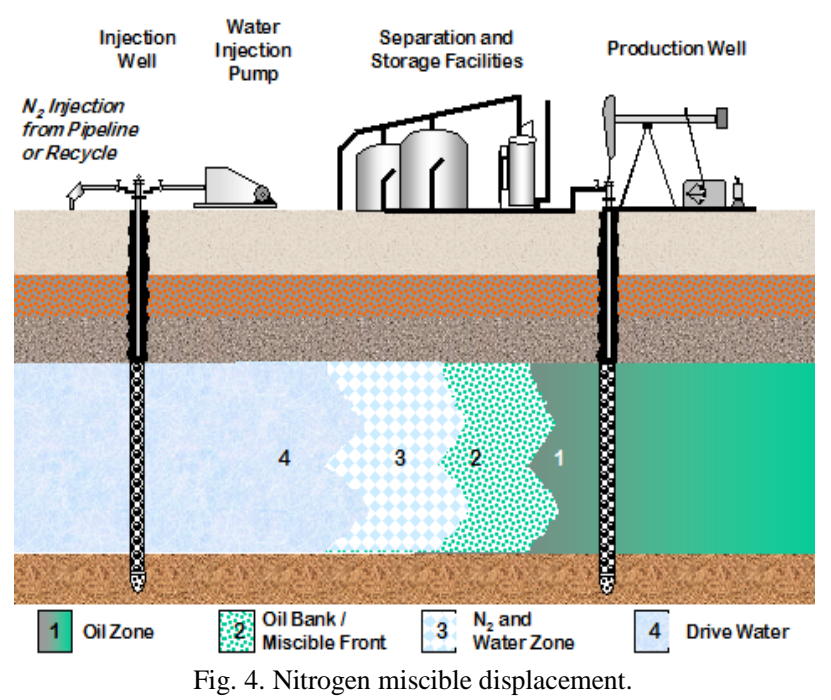

Gravity drainage: Gravity enhancement is by using the gravity drainage potential of a dipping or thick hydrocarbon zone. (Nitrogen, which usually has a lower density than the reservoir fluids, when injected into the crest or allowed to migrate to the crest, will enhance the down dip displacement and production of the reservoir fluids or of a gravity stable miscible slug) [26]. One of the most common gravity drainage processes is the Double Displacement Process (DDP), Fig. 5. This is done by injecting gas up -dip and producing oil down-dip [24], [27]. By using Gravity Drainage, piston like displacement is obtained, therefore gas fingering is avoided. In addition, the following results are obtained: Horizontal gas-oil contact; gravity dominate the gas flow; optimized time between gas injection and oil production as fast as possible; the greater the dip angle the higher the injection \& production rates w/o gas fingering; the greater the dip the more effective the gravity drainage [23].

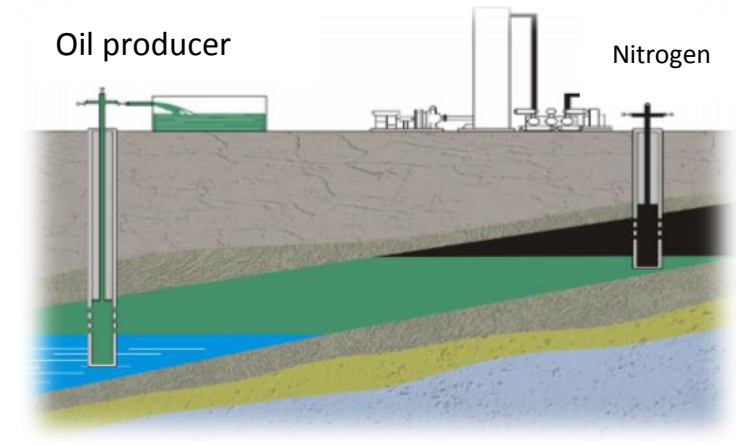

Fig. 5. DDP process (Gravity Drainage) [23].

\section{WHY IS NITROGEN?}

Nitrogen is the optimum EOR method for many reservoirs and has been chosen for the following reasons [22].
1) By applying nitrogen given the fact that a significant increase in oil production has been realized [28].

2) Nitrogen is economical (cheaper than $\mathrm{CO}_{2}$ [29], [30]. The membrane separation technology yields Nitrogen at a cost of approximately $\$ 1.00$ per MCF that contains volumetrically up to 5-percent Oxygen. Analysis of the field's production performance indicates that it requires the injection of approximately 2.5 MCF of Nitrogen to recover one barrel of oil [28].

3) Nitrogen can form a miscible slug if injected at high pressure [9].

4) Nitrogen has good injectivity in low permeability reservoirs [28].

5) Nitrogen can be generated and therefore can be injected wherever, whenever, and whatever quantities are needed [9].

6) Nitrogen is friendly to environment, completely inert [28], and remains inert in the presence of water [31].

7) Nitrogen is non-corrosive to field equipment [22], [30].

8) Nitrogen can be removed economically from a sales gas stream to increase Btu content (\$ 0.9 per MSCF) [32].

9) Nitrogen gas is less compressible than $\mathrm{CO}_{2}$ or natural gas, so less is required $\left(\mathrm{N}_{2}=0.9998\right.$ while it is 0.9949 for $\mathrm{CO}_{2}$ at $25 \mathrm{C}$ and 14.7 PSIA) [31].

10) Nitrogen is harmless compared to other gas (not flammable) [22].

11) Nitrogen vaporizes the lighter components of the crude oil and generates miscibility if the pressure is high enough [33].

12) Nitrogen provides a gas drive where a significant portion of the reservoir volume is filled with low cost gases [16] such as $\mathrm{CO}_{2}$ [26].

13) Nitrogen injection has the best pressure maintenance while $\mathrm{CO}_{2}$ injection has the least pressure maintenance control [20], [26].

14) Gravity enhancement [26], [34].

15) The choice of nitrogen instead of carbon dioxide as a substitute for hydrocarbon gas is mainly based on displacement characteristics (carbon dioxide would give viscous fingering and/ or severe gravity tonguing) density, $\mathrm{g} / \mathrm{cm}^{3}$ : carbon dioxide $=0.78$ nitrogen $=0.30$. Viscosity, CP: carbon dioxide $=0.07$, nitrogen $=0.03$ and on differences in costs (carbon dioxide being much more expensive) [34].

16) Although a solid asphaltene phase forms in the crude oil, it may not have any deposition tendencies, and as a result not cause any problems. Furthermore the experiments they had done was in purpose of maintaining reservoir pressure, in addition it was known to have operational problems due to asphaltene precipitation during primary production [35].

17) Nitrogen is most attractive both technical and economical solution [29].

18) It was noticed that molecular mass transfer between nitrogen gas and oil had occurred when nitrogen was injected, whereas oil has oxygen and carbon as its components. At higher injection rates, oxygen free gas percentage was less, probably due to oxidation process taking place, which used up oxygen in the oil during injection. This oxidation process helped increase the oil recovery [22]. 


\section{RESERVOIR SCREENING CRITERIA}

To apply nitrogen miscibility, light oils at high pressures and deep reservoirs are needed to achieve this miscibility. In addition, to permit gravity stabilization of the displacement, steeply dipping reservoirs are needed. However, conditions of rock and Fluid of reservoirs that nitrogen might be applied on them are mentioned by J. J. Taber and others [36]. They are as follows:
1) API gravity:
$35-48$
2) Viscosity:
$0.4 \mathrm{cp}$
3) Composition:
$\mathrm{C} 1-\mathrm{C} 7$
4) Oil saturation:
$>40 \%$ P.V.
5) Formation type:
sand stone/carbonate
6) Permeability :
O.K
7) Transmissibility:
not critical
8) Temperature:
9) Depth:
10) Thickness:
$>6000 \mathrm{ft}$
thin unless dipping

\section{Nitrogen injection problems:}

1) The gas is no longer a saleable product, therefore, Nonhydrocarbon gases must be separated from saleable gas [37].

2) The residue gas is no longer rich enough to be used as fuel gas for the plant and injection compressors [37].

3) Viscous fingering results occur in poor vertical and horizontal sweep efficiencies (due to the fact that the displacing fluid is less viscous than oil) [38].

4) Because of the density differences, solvents and drive gases may segregate and override the other reservoir fluids, causing what's known density fingering, which in turn decreases the vertical sweep in horizontal floods [33].

5) Flue gas and nitrogen have only limited application as agents of a miscible displacement in deep and high pressure reservoirs. For these reasons, EOR processes based on gas injection have not been as common as immiscible displacement processes [36].

\section{NitRogen OVERRIDE AND VisCOUS FINGERING}

Perhaps the best advantage of $\mathrm{N}_{2}$ flooding is that it can potentially be used anywhere in the world if it can be cheaply extracted from the air, where other injection fluids are either not available or the cost of their delivery to the oil reservoir is prohibitive. However, even if the gas that one wishes to use as a miscible displacement agent is economically available; its use is not without problems. [33]. In other words, the main problems, that encounters EOR engineers during gas injection are Override/Density Fingering and Viscous fingering [33], [39], [40].

Override or density fingering: The problem is that after some time and distance this mixture is separated by gravity. The gas is separated from the mixture and goes to the top of reservoir and overrides the oil, while water goes to the bottom of reservoir and under-rides the oil. This phenomenon usually called gravity segregation. Gravity segregation itself is a competition between gravity (and density difference) and lateral pressure gradient. It occurs when the injected fluid density is higher or lower than the reservoir fluid density. Gravity segregation leads to early breakthrough of the injected fluid and reduces vertical

sweep efficiency [41].

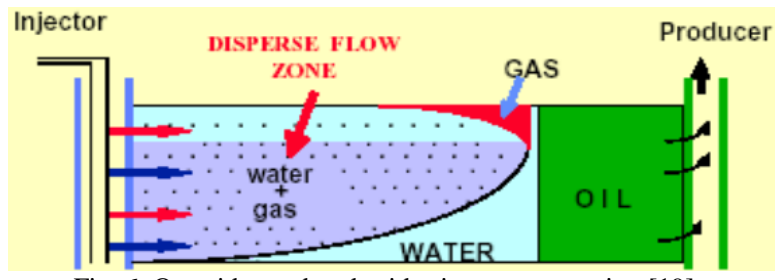

Fig. 6. Overrides and underrides in gas segregation [19].

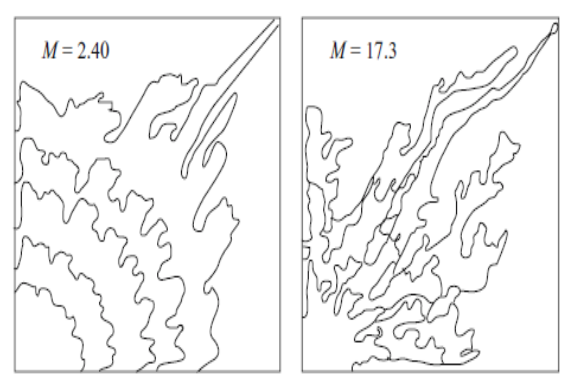

Fig. 7. Displacement fronts for two values of the mobility ratio $M$. The injection point is the lower left corner [33].

Moreover, when there is a substantial density difference between the displaced and the displacing fluids, gravity forces acting in the transverse direction may cause separation of the two fluids. In media of high permeability and/or for low displacement velocity, gravity may dominate the displacement. In that case most of the displacing fluid flows through a gravity tongue that grows on the top or the bottom of the medium. After the tongue breaks through vertically all the flow is channelled through it and the recovery efficiency is drastically reduced. This is what is termed as Gravity tonguing or density fingering [38]. Gravity causes more fluid to flow into the finger in the upper part of the slap, resulting a faster growth of that finger, while growth of the rest of the fingers is somewhat suppressed, partly because of gravity drainage and partly because of shielding, Fig. 6 [37].

Viscous fingering: When the injected gas and the fluids that are in the porous medium, are first contact miscible, as well as the mobility ratio $M<1$, then the displacement process is very simple and efficient. There is also a mixed zone between regions of pure displacing and displaced fluids. On the other hand, in practice the process of miscible displacement is not so simple. Therefore $M>1$, which means the front, is unstable and many fingers of the mixture of the gas and the displaced fluid develop, leaving behind large amounts of oil. The formation of the fingers, which have very irregular shapes, reduces strongly the efficiency of the miscible displacements. Fig. 7 illustrates the effect of the mobility ratio $\mathrm{M}$ on the formation and shape of the fingers. This phenomenon is usually referred to as viscous fingering because mobility is originally controlled by viscosity. Under field conditions, fingering may be dominated by the distribution of the heterogeneities of the porous formation and, therefore, one should simply refer to the phenomenon as fingering [33]. As $\mathrm{M}$ values become bigger, fingering becomes more apparent [38].

\section{SOLUTIONS}

Nitrogen can be replaced by $\mathrm{CO}_{2}$. Considering that oil 
recoveries per $1,000 \mathrm{cu} \mathrm{ft.}\left(28 \mathrm{~m}^{3}\right.$ (at reservoir pressure) may have been only slightly higher for $\mathrm{CO}_{2}$ than for nitrogen, the operator needed to consider other factors. Comparing nitrogen and $\mathrm{CO}_{2}$ costs compressibility, availability, and corrosive properties, one could see why nitrogen was selected [26].

Because of differences in density and viscosity between the injected fluid and the reservoir fluid(s), the miscible process often suffers from poor mobility. Viscous fingering and gravity override frequently occur. The simultaneous injection of a miscible agent and brine was suggested in order to take advantage of the high microscopic displacement efficiency of the miscible process and the high macroscopic displacement efficiency of a water flood. The improvement was not as good as hoped for since the miscible agent and brine tended to separate due to density differences, with the miscible agent flowing along the top of the porous medium and the brine along the bottom. Several variations of the simultaneous injection scheme have been suggested and researched. They typically involve the injection of a miscible agent followed by brine or the alternating of miscible agent-brine injection. The latter variation has been named the WAG (water alternate gas) process and has become the most popular [42].

Water alternating gas injection (WAG): Water Alternating Gas (WAG) is a process of injecting water followed by gas, followed by more water, followed by more gas, etc. The gas mixes with the water ahead of it, which causes a reduction in gas mobility. This mixture is effective in displacing oil to the production well, since the macroscopic sweep efficiency is larger than for gas injection only while microscopic efficiency is still high. This is why WAG can improve recovery factor [41]. Water Alternating Gas (WAG) injection is a combination of two conventional EOR techniques; water flooding and gas injection. In 1957, it was very first time applied on North Pembina field in Alberta, Canada by Mobil. The WAG was adopted by keeping this point of consideration into the mind that the traditional gas and water floods usually leave at least 20$50 \%$ of the residual oil in place. From the laboratory analysis it was calculated that simultaneous water/gas injection could have sweep efficiency up to $90 \%$ and only gas alone results in about $60 \%$. But later on this fact came in front that simultaneous injection of gas and water is impractical because of Mobility instabilities, then after alternate injection method of gas and water (WAG) was adopted. Also it was found to be quite economical. The initial proposed ratio of water and gas was 0.5:4 in frequencies of 0.1 to $2 \%$ Pore Volume slugs of each fluid that was being adopted according to the reservoir conditions [20]. Miscible WAG injection has been implemented successfully in a number of fields around the world [43]. In principle, it combines the benefits of miscible gas injection and water flooding by injecting the two fluids either simultaneously or alternatively [33]. A balance between amounts of injected water and gas must be achieved. Too much gas will lead to viscous fingering and gravity override of the gas, whereas too much water could lead to the trapping of reservoir oil by the water. The addition of foamgenerating substances to the brine phase has been suggested as a way to aid in reducing the mobility of the gas phase.
Research is continuing in this area [42].

Kulkarni, [44] described in Fig. 8, the problems associated with implementation of WAG: the gravity segregation effects' prominence increases as the injected fluids progress away from the wellbore, resulting in a large bypassed zone attributable to the gas over-ride and water under-ride as shown in Fig. 8. Fig. 8 clearly shows that although good conformance is achieved by employing the WAG process in the near-well bore region, the natural gravity segregation tendencies of gas and water eventually dominate the process, thereby resulting in a large un-swept region in the central portion of the reservoir. Furthermore, water injection for conformance control leads to other mechanistic problems such as increased three-phase relative permeability.

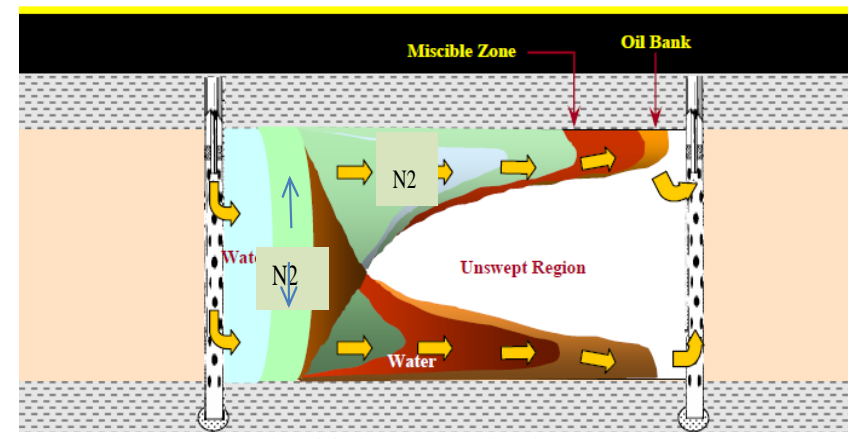

Fig. 8. schematic of fluids segregation in the reservoir [45]

\section{A. Nitrogen GAS $\left(\mathrm{N}_{2}\right) W A G$}

T.B. Jensen (2000) discussed the injecting of $\mathrm{N}_{2}$ by using WAG process on Ekofisk field. $\mathrm{He}$ conducted the displacement of water flood residual oil by injected $\mathrm{N}_{2}$ as much the same as that for $\mathrm{HC}$ WAG, although $\mathrm{N}_{2}$ (or flue gas) is less efficient than $\mathrm{HC}$ gas in vaporizing intermediate Ekofisk oil components. Laboratory experiments have shown that $\mathrm{N}_{2}$ is able to efficiently vaporize intermediate Ekofisk oil components only up to about C8 under field operating conditions. $\mathrm{N}_{2}$ injection is volumetrically more efficient (in terms of voidage replacement) than other injection gases being considered for EOR application at Ekofisk. Furthermore, no injectivity problems (hydrates) are expected with $\mathrm{N} 2$ gas injection based on thermodynamic considerations [45].

To solve problems resulting by density and viscosity fingering, Saif S. Al Sayari [46] suggested to inject gas at the lower zone. He added: there is no force to cause the injected gas to flow from the upper zone to the lower zone as it has lower or similar density as oil. Therefore, a method is required that confines the injected gas to the lower zone. A possible way of achieving this is by keeping the upper zone pressurized by continuous water injection and simultaneously injecting gas into the lower zone. In addition the densities of fluids used in miscible processes generally are significantly smaller than the densities of crude oils displaced. Hence nitrogen's density is less than oil's and reservoir fluids, which will make the nitrogen overrides and therefore density fingering will grow up [40].

1) Simultaneous Water Alternating Gas Process (SWAG)

WAG and (SWAG) injection techniques are both tertiary 
recovery techniques of oil combine the advantages of the waterflooding and gas injection methods to control the gas mobility and optimize the residual oil production but SWAG technique presents higher values of efficiency when compared with the WAG technique [47]. Christensen et al. (2001) defined the SWAG method as simultaneous injection of both water and gas at the same time into a portion or the entire thickness of the formation.

This process SWAG can be performed using two different techniques: Conventional SWAG technique, and Modified SWAG technique [48].

Conventional SWAG technique: Water and gas are mixed at the surface.

Modified (selected) SWAG technique (SSWAG): Gas and water are injected together through a single well bore, no mixing takes place at the surface. The two phases are pumped separately using a dual completion injector and are selectively injected into the formation. Usually gas is injected at the bottom of the formation and water is injected into the upper portion [49].

\section{2) Simultaneous Water Alternating Gas (SWAG Nitrogen)}

In 1981, Slack and Ehrlich (1981) examined simultaneous water and $\mathrm{N}_{2}$ (SWAN2) injection. They inferred that for reservoir rocks with favorable relative permeability characteristics, the displacement mechanism accomplished by SWAN2 injection was capable of causing displacement of significant amount of waterflood residual oil at reasonable water $/ \mathrm{N}_{2}$ ratios and in reasonable times.

\section{CONCLUSION}

After depletion of reservoir natural pressure drives, a secondary recovery stage is usually implemented in order to boost and maintain the reservoir pressure. When the recovery decline, EOR techniques are to be performed. One of these methods is Nitrogen injection, which was used as an alternative to carbon dioxide. Nitrogen was chosen because of its availability, it's noncorrosive, inert gas, friendly to environment, less compressible than $\mathrm{CO}_{2}$, and can vaporizes the lighter components of crude oil, and in addition nitrogen can provide a gas drive. On the other hand, applying nitrogen injection technique is usually associated with some problems. Although water alternating gas (WAG) is one of the solutions implemented to increase the recovery efficiency, at least two problems appeared and decreased the sweep efficiency by phenomena called Override and viscous fingering. Many studies have been implemented on these two problems, such as simultaneous water alternating gas processes, but still new developments and methods should be devised.

\section{REFERENCES}

[1] J. P. Meyer, Summary of Carbon Dioxide Enhanced Oil Recovery ( $\mathrm{CO}_{2}$ EOR) Injection Well Technology, American Petroleum Institute, p. 54, 2007.

[2] P. Glover, Formation Evaluation MSc Course Notes, Aberdeen University, pp. 19-26, 2001.

[3] R. Fleshman and O. Lekic, "Artificial lift for High-Volume production," Oilfield Review 11, pp. 48-63, 1999.

[4] L. Romero-Zerón, Advances in Enhanced Oil Recovery Processes, University of New Brunswick, Chemical Engineering Department, Canada, 2012.
[5] I. W. Newsletter. (2010). Drilling, oil spill solutions. [Online]. Available: http://www.oilspillsolutions.org/isco.htm

[6] Z. Abdulrazag and K. Jerbi, "Economic evaluation of enhanced oil recovery," Oil \& Gas Science and Technology, vol. 57, no. 3, pp. 259267, 2002.

[7] T. Isco, Enhanced_Oil_Recovery, 2012.

[8] L. W. Lake, "Fundamentals of enhanced oil recovery," Society of Petroleum Engineers, 1986.

[9] B. D. Al-Anazi, "Enhanced oil recovery techniques and nitrogen injection," CSEG Recorder, pp. 29-33, 2007.

[10] S. Kokal and A. Al-Kaabi, Enhanced Oil Recovery: Challenges \& Opportunities, World Petroleum Council: Official Publication, 2010.

[11] Sino Australia Oil \& Gas Pty, An Introduction to Enhanced Oil Recovery Techniques, 2013.

[12] T. A. Jelmert et al., Comparative Study of Different EOR Methods, 2010.

[13] E. Kermen, Thermal Enhancement of Water-Flooding in MediumHeavy Oil Recovery, in Applied Earth Sciences, Delft University of Technology, The Netherlands, 2011.

[14] S. J. Seni and T. G. Walter, Geothermal and Heavy oil Resources in Texas, US Department of Energy, Washington D.C., 1994.

[15] M. A. E. Ela et al., "Thermal heavy-oil recovery projects succeed in Egypt, Syria," Oil and Gas Journal, vol. 106, no. 48, pp. 40, 2008.

[16] V. Alvarado and E. Manrique, "Enhanced oil recovery: An update revie," Energies, vol. 3, no. 9, pp. 1529-1575, 2010.

[17] S. Kirk Raney et al., Surface and Subsurface Requirements for Successful Implementation of Offshore Chemical Enhanced Oil Recovery, 2011.

[18] A. Zare, "Simulation study of micellar/polymer flooding process in Sandpack," in Proc. The 2011 IAJC-ASEE International Conference, University of Hartford, 2011.

[19] M. M. Kulkarni, Immiscible and Miscible Gas-Oil Displacements in Porous Media, Louisiana State University, 2003.

[20] F. I. Syed, A. H. Tunio, and N. A. Ghirano, "Compositional analysis and screening for enhanced oil recovery processes in different reservoir and operating conditions," International Journal of Applied, vol. 1 , no. 4,2011

[21] L. S. Melzer and T. Midland. (2012). Carbon dioxide enhanced oil recovery $\left(\mathrm{CO}_{2}\right.$ EOR): Factors involved in adding carbon capture, utilization and storage (CCUS) to enhanced oil recovery. [Online]. Available: http://neori.org/Melzer_CO2EOR_CCUS_Feb2012.pdf

[22] S. Siregar et al., "Laboratory experiments on enhanced oil recovery with nitrogen injection," Journal of Engineering and Technological Sciences, vol. 39, no. 1, pp. 20-27, 2007.

[23] D. Walker, "Reserve growth \& higher recovery using nitrogen gas injection," Energy Summit' 08, Praxair Inc, 2008.

[24] J. Shine and M. Holtz, "Reserve growth \& Higher Recovery using Nitrogen gas injection," in Proc. 2008 Wyoming EOR/IOR Conference, The Wyoming Enhanced Oil Recovery Institute's: PRAXAIR. Inc, 2008.

[25] I. Juttner, "Oil displacement in miscible condition," RudarskoGeološko-NAFTNI Zbornik, vol. 9, no. 1, pp. 63-66, 1997.

[26] J. Clancy et al., "Analysis of nitrogen-injection projects to develop screening guides and offshore design criteria," Journal of Petroleum Technology, vol. 37, no. 6, pp. 1097-1104, 1985.

[27] M. Holtz, Immiscible Gas Displacement Recovery, PRAXAIR, 2012.

[28] M. J. Farias and R. W. Watson, Interaction of Nitrogen/CO $\mathrm{O}_{2}$ Mixtures with Crude Oil, Pennsylvania State University, University Park, PA, USA, 2007.

[29] K. Watt, Proceeding of EORI Conference Altrnative Gas Injection Processes, 2012.

[30] D. A. Hudgins, F. M. Llave, and F. T. Chung, "Nitrogen miscible displacement of light crude oil: a laboratory study," SPE Reservoir Engineering, vol. 5, no. 1, pp. 100-106, 1990.

[31] Air. Productsand.chemicals. Inc., Increased Production through Enhanced-Oil-Recovery, 2009.

[32] P. E. M. Mitariten, "Economic-N2-removal-hydrocarbon-engineering," Hydrocarbon Engineering Magazine, 2009.

[33] M. Sahimi, M. R. Rasaei, and M. Haghighi, "Gas injection and fingering in porous media," Gas Transport in Porous Media, Springer, pp. 133-168, 2006

[34] P. Bath, Enhanced oil Recovery in the North Sea, 1987.

[35] A. Jamaluddin et al., "An investigation of asphaltene instability under nitrogen injection," in Proc. SPE International Petroleum Conference and Exhibition in Mexico, 2002.

[36] J. Taber, F. Martin, and R. Seright, "EOR screening criteria revisitedPart 1: Introduction to screening criteria and enhanced recovery field projects," SPE Reservoir Engineering, vol. 12, no. 3, pp. 189-198, 1997. 
[37] C. Mayne and R. Pendleton, "Fordoche: An enhanced oil recovery project utilizing high-pressure methane and nitrogen injection," in Proc. International Meeting on Petroleum Engineering, 1986.

[38] D. Moissis, "Simulation of viscous fingering during miscible displacement in nonuniform porous media," Tech. Rep. 88-89, Dep. of Math. Sci., Rice Univ., Houston, Tex 1988.

[39] R. Booth, Miscible Flow through Porous Media, University of Oxford, 2008.

[40] D. W. Green and G. P. Willhite, Enhanced Oil Recovery, Richardson, Tex.: Henry L. Doherty Memorial Fund of AIME, Society of Petroleum Engineers, 1998.

[41] A. Faisal et al., "Injectivity and gravity segregation in WAG and SWAG enhanced oil recovery," in Proc. SPE Annual Technical Conference and Exhibition, 2009.

[42] R. E. Terry, Enhanced Oil Recovery, pp. 503-518, 2000.

[43] J. R. Christensen, E. H. Stenby, and A. Skauge, "Compositional and relative permeability hysteresis effects on near-miscible WAG," in Proc. Symposium on Improved oil Recovery, 1998.

[44] M. M. Kulkarni, Multiphase Mechanisms and Fluid Dynamics in Gas Injection Enhanced Oil Recovery Processes, Louisiana State University, 2005.

[45] T. Jensen, K. Harpole, and A. Østhus. "EOR screening for Ekofisk," in Proc. European Petroleum Conference, 2000.

[46] S. S. Al Sayari, The Influence of Wettability and Carbon Dioxide Injection on Hydrocarbon Recovery, Imperial College London, 2009.

[47] H. L. M. Nangacovié, Application of WAG and SWAG Injection Techniques in Norne E-Segment, 2012.

[48] M. K. Algharaib et al., "Parametric investigations of a modified swag injection technique," in Proc. SPE Middle East Oil and Gas Show and Conference, 2007.
[49] M. T. Barnawi. (2008). A simulation study to verify stone's simultaneous water and gas injection performance in a 5-spot pattern. Master's thesis. Texas A\&M University. [Online]. Available: http://hdl. handle. net/1969

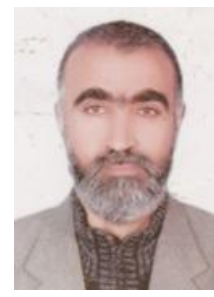

Abubaker Hamza Alagorni was born in Meslata, Libya in 1969. In 1994, he achieved the B.Sc. degree in petroleum engineering from the Faculty of Petroleum Engineering, University of Tripoli. In 2002, he got a M.Sc. degree from Newcastle University, England in process control. He started his $\mathrm{Ph} . \mathrm{D}$. degree at Universiti Malaysia Pahang (UMP), Department of Chemical and Natural Resources Engineering, under a research title "The influence of Simultaneous Water Alternating Gas (SWAG) on hydrocarbon recovery by using nitrogen injection", under supervision of Prof. Dr. Thulkefli Bin Yaacob and Prof. Dr. Abdurahman H. Nour. The research is still in progress.

In 1997, he started to work at Agip Oil Company to be a Rimal field production supervisor in 1999. He became an operation engineer in the electrical company, operation management, for almost three years from 2004 to 2006. He became a teaching staff in 2006 in the Faculty of the Engineering Technologies until he has started his Ph.D. degree in UMP, Malaysia.

Mr. abubaker is a member of the engineers in the city of Meslata. Many certificates have been awarded to him during his work in Agip Oil Company as well as in teaching period. He participated in preparing the Curriculum of the faculty of engineering technologies. 